ORIGINAL ARTICLE

\title{
Do factors in the psychosocial work environment mediate the effect of socioeconomic position on the risk of myocardial infarction? Study from the Copenhagen Centre for Prospective Population Studies
}

\author{
I Andersen, H Burr, T S Kristensen, M Gamborg, M Osler, E Prescott, F Diderichsen
}

Occup Environ Med 2004;61:886-892. doi: 10.1136/oem.2004.013417

See end of article for authors' affiliations

Correspondence to:

Mrs I Andersen, Institute of

Preventive Medicine,

Danish Epidemiology

Science Centre, $\mathrm{H}: \mathrm{S}$

Kommunehospitalet, DK-

1399 Copenhagen,

Denmark; ia@ipm.hosp.dk

Accepted 19 May 2004

\begin{abstract}
Aim: To investigate whether the effect of socioeconomic position on risk of myocardial infarction (MI) is mediated by differential exposure or differential susceptibility to psychosocial work environment.

Methods: Data were used from three prospective population studies conducted in Copenhagen. A total of 16214 employees, 44\% women, aged 20-75 years, with initial examination between 1974 and 1992 were followed until 1996 for incident (hospital admission or death) MI. Register based information on job categories was used. Psychosocial job exposures were measured indirectly by means of a job exposure matrix based on the Danish Work Environment Cohort Study 1990.

Results: During follow up, 731 subjects were diagnosed with an Ml: 610 men and 121 women ( $35 \%$ fatal). The hazards by socioeconomic position showed a graded effect with a hazard ratio (HR) of $1.57(95 \% \mathrm{Cl}$ 1.23 to 2.03) for unskilled workers compared to executive managers. Despite a strong and graded association in risk of $\mathrm{Ml}$ related to decision authority and skill discretion, only skill discretion mediated the effect of socioeconomic position. The HR for unskilled workers was reduced to 1.47 (0.93 to 2.31) after adjustment for decision authority and other cardiovascular risk factors, and to $1.07(0.72$ to 1.60$)$ after adjustment for skill discretion and cardiovascular risk factors. No sign of synergy was found.

Conclusions: Decision authority and skill discretion were strongly related to socioeconomic position; and the effect on risk of MI was partially mediated by skill discretion. Improvements in psychosocial work environment, especially possibilities for skill discretion, might contribute to reducing the incidence of $\mathrm{Ml}$ and social inequality in MI.
\end{abstract}

$\mathrm{S}$ tudies from a broad range of countries during the last 40 years have consistently shown that the risk of coronary heart disease is lowest in positions with greatest social and economic advantage, and highest in the most disadvantaged groups. The Whitehall II studies' 10 year follow up showed that, compared to the highest grade, men in the lowest grade had three times the mortality rate from coronary heart disease. ${ }^{1}$ The 25 year follow up found the mortality rate ratio of myocardial infarction (MI) for lowest versus highest grade to be $1.85 .^{2}$ A large Swedish case-referent study (SHEEP) found an OR of first MI for manual work compared to non-manual of 1.6 (95\% CI 1.4 to 1.9$).^{3}$ The Finnish Kuopio studies showed that the relative hazards (HR) of the incidence of MI were 2.59 ( 1.36 to 4.94 ) for low income men. ${ }^{4}$ The association between social class and risk of MI in a Danish context has been studied in cohort studies, where the mortality rate ratio in men aged 45-59 years, for manual versus non-manual classes, was 1.28 (1.23 to 1.33$).^{5}$ The prospective Copenhagen Male Study, from which we use data in our current study, found that, compared to highest social position, men in the lowest position had a relative risk of ischaemic heart disease (IHD) of 1.44 (1.1 to 1.9). ${ }^{6}$ The association between income and risk of IHD in a larger Danish cohort showed that when compared to high income there was an HR of 1.73 (1.42 to 2.11) for low income men and 1.99 ( 1.58 to 2.51 ) for low income women. ${ }^{7}$ This cohort is also included in the Copenhagen Centre for Prospective Population Studies.

The effect of social position on MI has been shown to be mediated by several known biological, behavioural, and psychosocial risk factors. ${ }^{8}$ Mediating factors are those that are causal intermediates in the pathway from social position to MI. They are not confounders, but part of the effect that we wish to study. ${ }^{10}$ Hallqvist et al have earlier pointed out that the causal pathway may involve two different mechanisms: differential exposure and differential susceptibility. ${ }^{9}$ Different social positions might be differentially exposed to the mediating cause. The effect of the mediating cause might also be modified by the social position. This typically occurs if one mediating cause interacts with another mediating cause related to social position. In accordance with Rothman and Greenland, ${ }^{10}$ an interaction is defined as two contributing causes that are part of the same sufficient cause. The empirical criterion is that the absolute effect of the mediating cause differs across social positions.

Among well known cardiovascular risk factors, smoking in particular shows a strong social gradient; ${ }^{11}$ but that is true for an increasing number of other cardiovascular disease risk factors. ${ }^{12}$ Most studies, however, have found that adjustment for a number of potentially mediating biological and behavioural risk factors reduces the excess risk among

Abbreviations: BMl, body mass index; CCHS, The Copenhagen City Heart Studies; CHD, coronary heart disease; CMS, The Copenhagen Male Study; DWECS, Danish Work Environment Cohort Study; ECM, Employment Classification Module; GPS, The Glostrup Population Studies; HR, hazard ratio; IHD, ischaemic heart disease; ISIC, International Standard Classification of all Economic Activity; JEM, job exposure matrix; MI, myocardial infarction; MONICA, MONltoring Trends and Determinants in CArdiovascular Diseases; SBP, systolic blood pressure; SHEEP, Stockholm Heart Epidemiology Program 


\section{Main messages}

- There is a graded effect of socioeconomic position on $\mathrm{MI}$, even in a welfare country.

- There is a strong and graded association between decision authority, skill discretion, and risk of MI.

- Only skill discretion mediates the effect of socioeconomic position on MI.

- It is important to split decision latitude and analyse decision authority and skill discretion separately.

manual occupations to only $20-50 \% .^{13}{ }^{14}$ If psychosocial exposures are included in the model, a similar proportion seems to be mediated by those causes. Several studies have found that the psychosocial conditions at the workplace are particularly important.

The Karasek-Theorell job strain model, which proposes the theory that workers who have the combination of excessive psychological demand and lack of decision latitude-that is, job strain, are at increased risk of coronary heart disease (CHD), has been tested in a number of studies. ${ }^{31315-25}$ However, reviews have provided only partial support for this two factor model. ${ }^{26}{ }^{27}$ Some studies have found that low job control, but neither job strain nor high demands, were associated with CHD. ${ }^{3} 16172028$ Extended follow up of the Whitehall II study showed that high demands were related to fatal CHD/non-fatal MI for men and women, whereas low decision latitude was predictive only of all CHD in men. ${ }^{22} \mathrm{~A}$ Finnish study found excess risk for high job strain, and low job control, but not for high demands among industrial employees. ${ }^{29}$

The mediating effect of job strain has been studied in the Copenhagen Male Study, which, despite pronounced differences across social positions in self assessed psychosocial working conditions, did not find job strain to be associated with increased risk of IHD. The study included relatively few end points, had quite a short follow up, and only followed men. ${ }^{30}$ In the Whitehall II, CHD endpoints and information on work environment were self reported, which makes reporting bias possible. Furthermore, the study group was by nature very homogeneous, including only London civil servants aged $35-55$ years. ${ }^{22}$ The Swedish SHEEP study found support for the effect of job strain. ${ }^{9}$ SHEEP showed not only a synergistic interaction between job demand and decision latitude, but also between socioeconomic status and job strain, resulting in increased effects of job strain on MI among male manual workers.

As the results in Denmark and elsewhere are still somewhat conflicting, and only few studies have been able to include women and study incident MI with a careful adjustment for potential confounders and mediators, this study will further investigate whether psychosocial working conditions mediate an expected effect of social position on the risk of incident MI in a Danish population. This prospective study includes both sexes and uses register based information on incident MI as well as on occupation. The study explores whether the social difference in risk of MI is, at least partially, mediated by differential exposure or by differential susceptibility.

\section{METHODS}

\section{Study population}

The study is based on data from three population based cohort studies, conducted in Copenhagen, and combined in the Copenhagen Centre for Prospective Population Studies: The Copenhagen City Heart Studies (CCHS), ${ }^{31}$ The

\section{Policy implications}

- Social inequalities in health and incident MI might be reduced by improvements in skill discretion, especially among unskilled workers.

Copenhagen Male Study (CMS), ${ }^{32-34}$ and The Glostrup Population Studies (GPS). ${ }^{35}{ }^{36}$

The CCHS comprised 14119 randomly selected men and women, aged 20+ years, from a geographically defined area of central Copenhagen. The subjects were examined initially between 1976 and 1978. Between 1981 and 1983, the subjects were re-examined, and 1560 new subjects were included. The CCHS thus consisted of 15679 subjects.

The CMS was established in 1970-71, consisting of 5249 men, aged between 40 and 59 years, from 14 larger public and private workplaces in Copenhagen. A new baseline was established in 1985-86, formed by re-examination of 3354 men, aged 53-75 years. For this study, we used data from the second baseline, which provided information on current and previous diseases and symptoms, lifestyle factors, and psychosocial factors.

The GPS have, since 1964, followed different birth cohorts in the populations of selected Western suburbs of Copenhagen, which, during the study period, have changed from partly rural to almost exclusively suburban residential areas. Three of these cohorts are part of the MONICA (MONItoring Trends and Determinants in CArdiovascular Diseases) investigations. All cohorts had a similar distribution of men and women. For this study, it was possible to use data from five different cohorts born between 1914 and 1962 and examined between 1974 and 1992. The GPS population for this study consisted of 9230 subjects.

\section{Data on social position}

In this study, social position was measured by occupation. We included only individuals employed at the time when occupation was registered. The employees were divided into five positions according to occupation and position at work. These five positions are closely related to education.

Information on occupation was obtained by means of a linkage between the individual civil registration number and the Employment Classification Module (ECM). ECM is based on different administrative registers and contains information on: type and level of income; conditions and type of employment; and place of work. ECM includes all citizens above 16 years who have a certain small income. Persons with varying jobs during a calendar year are classified according to the employment which resulted in the highest pay. ${ }^{37}$ The five digit occupational classification combines the first three digits of an industry classification (International Standard Classification of all Economic Activity, ISIC, version 1968) and a two digit classification of social position.

We obtained the ISIC coding for the study population for each of the years 1980-96. For subjects examined from 1974 to 1980, we used the coding from 1980. Otherwise, we used the occupation code from the year of the baseline investigation used in this study. If the coding was "position unknown", and this coding changed during the following five years, we used the first "ordinary" coding. Coding was changed for 952 subjects.

\section{Measures of psychosocial working conditions}

There were no direct questions of self reported psychosocial work environment in the cohorts. Information on 
psychosocial job exposure was therefore measured indirectly by means of a job exposure matrix (JEM). The JEM is a job classification system, based on aggregated job descriptive data derived from questionnaires from representative samples of employees in the population. ${ }^{38} 39$

The JEM is based on the Danish Work Environment Cohort Study (DWECS). In 1990, a representative sample of 5940 adults aged $18-59$ years, who had been working as employees for at least two months, was interviewed by telephone according to a questionnaire containing, among others, 23 questions on psychosocial factors at work. Each question had 4-6 response options. On the basis of factor analysis, the 23 items were combined into six scales, each measuring a dimension of the psychosocial work environment: psychological job demand; decision authority; social support; skill discretion; conflicts at work; and job insecurity. ${ }^{40}$ Skill discretion is the opportunity to develop new skills at work independent of previous education.

All dimensions were transformed so that the minimum value was 0 and the maximum was 100, with equal weight given to the individual questions in the dimension. All employees were interviewed about the industry of their company, their social position, and their education. On the basis of these answers, job in DWECS was classified by means of the job classification combining ISIC (version 1968) and social positions, as in the Employment Classification Module.

In DWECS, information was gathered for 90 jobs for women and 134 for men. The two sexes had 76 jobs in common. Among women, 54 jobs had fewer than 10 subjects in the DWECS sample. Among men, 59 jobs had fewer than 10 subjects in the DWECS sample. For these occupations, we applied a simplified matrix based on measurements from DWECS, combining the five social positions and six main industries, where only the two first digits of ISIC were used. We then linked the JEM to the cohorts through sex and job title.

\section{Confounding and/or mediating exposures}

In the cohorts, a broad range of well known contributing causes of MI was assessed for each participant at each examination using self administered questionnaires, clinical examinations, and blood samples. Although phrasing of questions differed slightly in various sub-cohorts, it was possible to maintain sufficient consistency in the covariates used for this investigation.

- Smoking behaviour was determined using questions to categorise smokers according to present tobacco consumption. Current smoking status was categorised into five groups according to rate of tobacco consumption, but regardless of inhalation and type of tobacco (never, ex, 1-14 g/day, 15-24 g/day, $\geqslant 25 \mathrm{~g} /$ day).

- Alcohol intake was categorised into four groups (0, 1-2, 3-5, $>5$ drinks/day).

- Physical activity in leisure time was divided into three groups, measured in hours per week (none/little, moderate 2-4 h, moderate $>4 \mathrm{~h} /$ hard work $2-4 \mathrm{~h} /$ competition $>4 \mathrm{~h}$ ).

The participants were also given a health examination with anthropometrical measurements and various laboratory tests.

- Body mass index (BMI), based on data collected by trained nurses, was calculated as weight in kilograms divided by height in metres squared. In the present study, BMI was categorised into five groups $(<22,22-24,25-27,28-32$, $>32$ ).

- Systolic blood pressure (SBP) and blood lipids measured as total cholesterol were divided into quintiles within cohorts, in order to avoid systematic errors in measurement between cohorts.

Information on risk factors was collected at baseline; and no control for changes in risk factors during follow up was attempted in the main analysis. Information on cohabitation

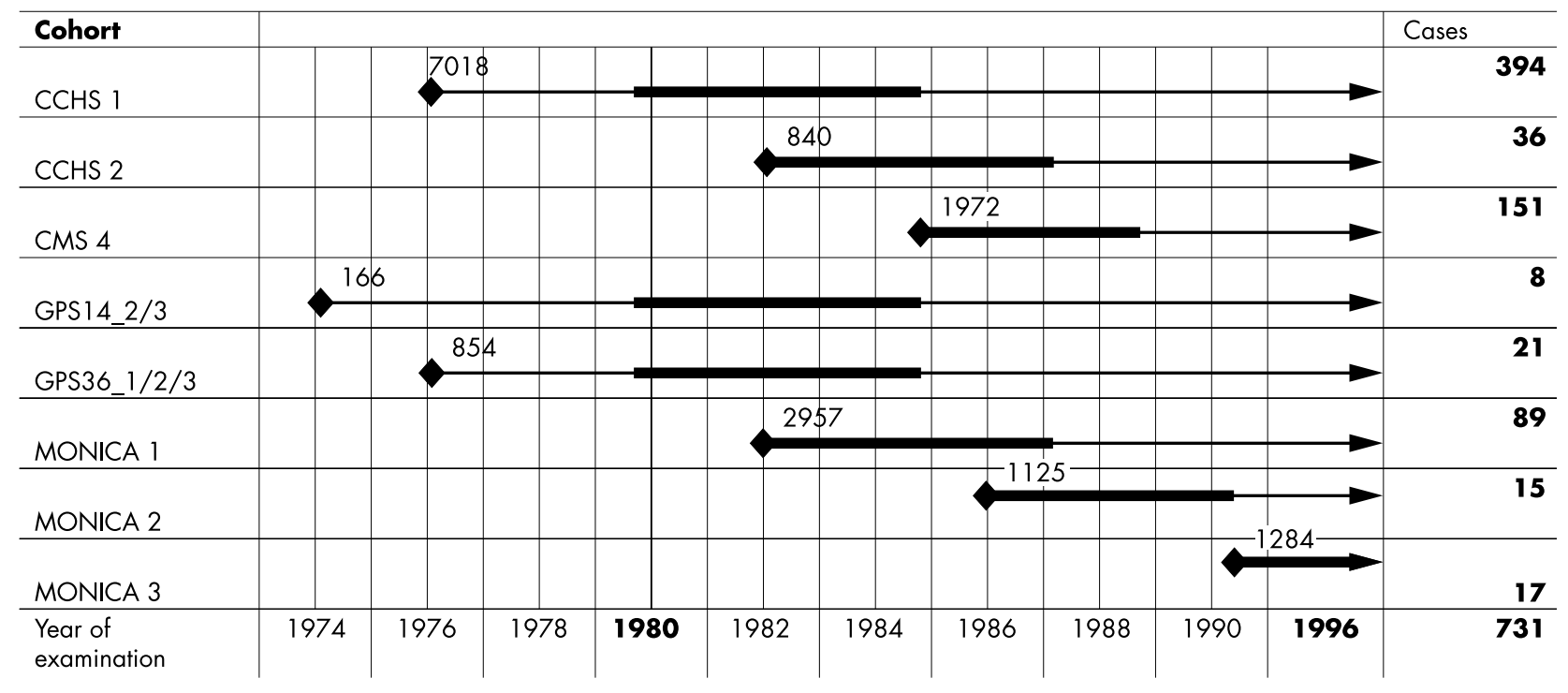

CCHS 1 Copenhagen City Heart Studies first examination

CCHS 2 Copenhagen City Heart Studies second examination - number of new subjects included

CMS 4 Copenhagen Male Study, data from fourth examination

GPS1914_2 Glostrup Population Study birth cohort 1914, data from second examination, new subjects in third

GPS1936_1 Glostrup Population Study birth cohort 1936, data from first examination

MONICA 1 First MONICA study

The 5 years during which the occupational coding was obtained, if coding at entrance was "position unknown"

Figure 1 A total of 16216 subjects from cohorts included in the study, defined by cohort and year of examination. 
Table 1 Baseline characteristics of social positions in the Copenhagen Centre for Prospective Population Studies

\begin{tabular}{|c|c|c|c|c|c|c|c|}
\hline & & $\begin{array}{l}\text { Executive } \\
\text { managers/ } \\
\text { academics } \\
n=2153\end{array}$ & $\begin{array}{l}\text { Leading } \\
\text { managers } \\
n=2884\end{array}$ & $\begin{array}{l}\text { Salaried } \\
\text { employees } \\
n=5395\end{array}$ & $\begin{array}{l}\text { Skilled workers } \\
n=2114\end{array}$ & $\begin{array}{l}\text { Unskilled workers } \\
n=3670\end{array}$ & $\begin{array}{l}\text { Test for trend } \\
\text { p value* }\end{array}$ \\
\hline Females & $\%$ & 18.8 & 36.8 & 66.4 & 5.3 & 52.5 & \\
\hline Mean age, $y$ & & 50.5 & 49.3 & 48.3 & 49.9 & 49.5 & \\
\hline Heavy smokers: $>15 \mathrm{~g} /$ day & $\%$ & 31.4 & 31.7 & 33.7 & 42.4 & 41.8 & $<0.001$ \\
\hline Alcohol: $>5$ drinks/day & $\%$ & 12.0 & 13.3 & 16.9 & 25.3 & 32.5 & $<0.001$ \\
\hline Physical activity: none/little & $\%$ & 15.1 & 16.2 & 19.9 & 15.8 & 25.7 & $<0.001$ \\
\hline BMl, $\mathrm{kg} / \mathrm{m}^{2} \geqslant 32$ & $\%$ & 2.5 & 3.8 & 3.8 & 4.9 & 7.6 & $<0.001$ \\
\hline $\mathrm{SBP}, \mathrm{mm} \mathrm{Hg}$ & & 128 & 126 & 125 & 128 & 129 & 0.06 \\
\hline Cholesterol, mmol/l & & 5.96 & 5.96 & 5.96 & 6.13 & 6.05 & $<0.001$ \\
\hline Education $(<8 \mathrm{y})$ & $\%$ & 7.3 & 23.5 & 31.8 & 49.8 & 65.8 & $<0.001$ \\
\hline Living alone & $\%$ & 17.4 & 20.4 & 24.2 & 13.8 & 23.1 & 0.013 \\
\hline Decision authority & $(0-100)$ & 86.6 & 84.6 & 74.5 & 72.3 & 63.9 & $<0.001$ \\
\hline Demands & $(0-100)$ & 37.0 & 34.8 & 30.2 & 27.5 & 24.3 & $<0.001$ \\
\hline Skill discretion & $(0-100)$ & 34.4 & 30.8 & 27.3 & 26.0 & 16.9 & $<0.001$ \\
\hline Social support at work & $(0-100)$ & 75.8 & 75.1 & 77.7 & 77.3 & 71.8 & $<0.001$ \\
\hline
\end{tabular}

was obtained from registers. People were defined as cohabiting if they were married or lived together with another adult person.

\section{Follow up}

Subjects were examined during 1974-92, and were followed up on MI incidence until 31 December 1996. The first linkage between study population and register data on occupation, however, was in 1980. Consequently, the follow up started in 1980 or at study entry, whichever was latest. As illustrated in fig 1, subjects included before 1980 could therefore have a gap of up to six years between examination and register information on occupation. Information regarding psychosocial working conditions was collected in 1990. This information was used to describe psychosocial working conditions for occupations from 1980 to 1996. Series of DWECS, however, have shown that the within-job distribution for the main psychosocial working conditions is very stable, $^{41}$ and that the time gap resulted in no significant limitations to the study design. It seems as if the risk of developing MI does not develop rapidly, but increases over time. ${ }^{3}$ Since we were concerned with the association between job exposure and MI, subjects were censored five years after retirement, which occurred at age 67 . A few people continued to work after that age, and we censored them at age 75 .

\section{End point}

End point was defined as incidence of first MI, whether fatal or non-fatal. Cause of death was obtained from the National Death register and cases of inpatient care for acute MI were obtained from the National Hospital Discharge Register. MI was defined according to the International Classification of Diseases: 8th revision code 410, and 10th revision code I21I22. Validity studies of the data submitted to The National
Hospital Discharge Register on MI have indicated that register based data are sufficiently reliable. ${ }^{42}$

The combined study population comprised 28263 subjects. A total of 12047 subjects were non-eligible due to the following: occupation coded as self employed (1827); retired (5971); not economically active (1975); and insufficient (990) or missing data on occupation (765). Other exclusions were caused by lack of information of the following key variables: blood pressure, cholesterol, BMI, tobacco, physical activity, and alcohol (in total 519 subjects). This resulted in a study population of 16216 subjects: 7086 women and 9130 men. The study covered a total of 183354 person-years.

\section{Statistical methods}

The trend tests of the baseline characteristics were performed with a non-parametric test for trend across ordered groups. ${ }^{44}$ The association between risk factors and incidence of MI was analysed using Cox's proportional hazards regression models, with age as underlying time scale. A basic Cox model was developed that included social positions, with adjustment for cohort of investigation and marital status. In a second series of models, the covariates tobacco, alcohol, physical activity in leisure time, SBP, cholesterol, and BMI were each entered separately as categorical covariates, as described above. In a third model, we tested for psychological job demand, decision authority, skill discretion, and social support at work. These variables were divided in quartiles based on the scales from the present study population. The proportional hazards assumption was evaluated for all variables by comparing estimated log-log survivor curves over the different categories of variables being investigated, and by tests based on the generalisation of Grambsch and Therneau. ${ }^{43}$ All covariates were tested for interaction with social positions by means of the likelihood ratio test. Initial survival analyses were carried

Table 2 Hazard ratios and $95 \% \mathrm{Cl}$ of $\mathrm{Ml}$ by dimensions of psychosocial working conditions, based on 9130 men and 7086 women from the Copenhagen Centre for Prospective Population Studies

\begin{tabular}{|c|c|c|c|c|c|c|c|c|}
\hline & \multicolumn{2}{|c|}{ Decision authority* } & \multicolumn{2}{|c|}{ Skill discretion* } & \multicolumn{2}{|c|}{ Social support ${ }^{\star}$} & \multicolumn{2}{|c|}{ Demand ${ }^{*} \dagger$} \\
\hline & HR & $(95 \% \mathrm{Cl})$ & HR & $(95 \% \mathrm{Cl})$ & HR & $(95 \% \mathrm{Cl})$ & HR & $(95 \% \mathrm{Cl})$ \\
\hline 1. quartile (highest) & 1 & & 1 & & 1 & & 1 & \\
\hline 2. quartile & 1.08 & $(0.86$ to 1.36$)$ & 1.35 & (1.08 to 1.71$)$ & 1.32 & (1.00 to 1.73$)$ & 1.09 & (0.88 to 1.35$)$ \\
\hline 3. quartile & 1.11 & $(0.91$ to 1.36$)$ & 1.28 & (1.04 to 1.58 ) & 1.11 & (0.84 to 1.47 ) & 1.05 & $(0.85$ to 1.30$)$ \\
\hline 4. quartile (lowest) & 1.26 & (1.04 to 1.54 ) & 1.52 & (1.22 to 1.89 ) & 1.12 & $(0.84$ to 1.48$)$ & 1.01 & (0.82 to 1.25 ) \\
\hline
\end{tabular}

*Adjusted for cohort of investigation, age, cohabitation, and sex, as described in the text.

tFor "demand", lowest quartile is reference and 4th quartile is highest. 
Table 3 Hazard ratios and $95 \% \mathrm{Cl}$ of MI by social positions based on 9130 men and 7086 women from the Copenhagen Centre for Prospective Population Studies; the mediating effect of separately including dimensions of psychosocial working conditions in quartiles to the basic model

\begin{tabular}{|c|c|c|c|c|c|c|c|c|c|}
\hline \multirow[b]{2}{*}{ Social position } & \multirow{2}{*}{$\begin{array}{l}\text { Cases of } \\
\mathrm{MI}\end{array}$} & \multicolumn{2}{|c|}{ Basic model* } & \multicolumn{2}{|c|}{ Full model† } & \multicolumn{2}{|c|}{$\begin{array}{l}\text { Full model† + Decision } \\
\text { authority }\end{array}$} & \multicolumn{2}{|c|}{$\begin{array}{l}\text { Full model† + Skill } \\
\text { discretion }\end{array}$} \\
\hline & & HR & $(95 \% \mathrm{Cl})$ & HR & $(95 \% \mathrm{Cl})$ & HR & $(95 \% \mathrm{Cl})$ & HR & (95\% Cl) \\
\hline Executive managers & 92 & 1 & - & 1 & & 1 & - & 1 & - \\
\hline Leading managers & 128 & 1.31 & (1.01 to 1.70$)$ & 1.26 & (0.97 to 1.64 ) & 1.27 & (0.98 to 1.65$)$ & 1.08 & (0.78 to 1.49 ) \\
\hline Salaried employees & 117 & 1.36 & (1.06 to 1.76$)$ & 1.24 & $(0.96$ to 1.60$)$ & 1.33 & (0.91 to 1.93 ) & 1.05 & (0.75 to 1.48 ) \\
\hline Skilled workers & 127 & 1.27 & (0.97 to 1.66 ) & 1.17 & (0.90 to 1.53 ) & 1.26 & (0.79 to 2.01 ) & 1.03 & (0.72 to 1.47 ) \\
\hline Unskilled workers & 146 & 1.57 & (1.23 to 2.03 ) & 1.33 & (1.03 to 1.73 ) & 1.47 & (0.93 to 2.31$)$ & 1.07 & (0.72 to 1.60 ) \\
\hline
\end{tabular}

*Adjusted for cohort of investigation, age, cohabitation, and sex, as described in the text.

†Adjusted for cohort of investigation, age, cohabitation, tobacco, BMI, alcohol, physical activity, SBP, cholesterol, and sex, as described in the text.

out separately for women and men. Since the associations were similar, all analyses were founded on pooled data, in a model allowing different baseline hazards for women and men. Statistical analysis was performed using STATA for Windows version $7 .^{44}$

\section{RESULTS}

During follow up, 731 subjects were diagnosed with an MI: 610 men and 121 women. Two hundred fifty six events (35\%) were fatal. Table 1 gives baseline data of the study population by socioeconomic position. The data show, as verified by trend test, a notable social gradient in the exposure to decision authority, skill discretion, and job demands, as well as heavy smoking, BMI, and physical inactivity.

Table 2 presents the associations between job demands, decision authority, skill discretion, and social support at work and MI incidence. Low decision authority and each level of skill discretion were related to high risk, while the other dimensions seemed unrelated. After adjustment for all risk factors the results were attenuated and remained significant regarding skill discretion: HR for 2nd quartile 1.33 (95\% CI 1.05 to 1.67 ); HR for 4th (lowest) quartile: 1.35 (95\% CI 1.08 to 1.68$)$.

Initial analyses of association between social position and risk of MI, adjusted for sociodemographic confounders (table 3) show a clear social gradient in risk of MI. When traditional risk factors are included in the model the estimates remain significant, but only regarding unskilled workers. Despite the strong relation between social position and psychosocial working conditions (table 1) and a graded association in risk of MI related to decision authority and skill discretion (table 2), only skill discretion changed the estimates of socioeconomic position when entered in the simple model (data not shown). As table 3 shows, the inclusion of traditional cardiovascular risk factors and decision authority reduced the HR of unskilled workers to 1.47 (95\% CI 0.93 to 2.31 ). When traditional cardiovascular risk factors and skill discretion were included in the model, the HR for unskilled workers compared to executive managers was reduced to 1.07 (0.72 to 1.60$)$.
We dichotomised social positions, decision authority, and skill discretion. The aim of dichotomisation is to maximise the power for the interaction in order to investigate whether any difference could be explained by the mechanisms of differential susceptibility. The magnitude of the effect from exposure to low decision authority and low skill discretion depends on how the exposed and unexposed positions of each dimension are categorised. ${ }^{9}$ We tried different cut points in relation to exposure and social position. The contrast in exposure was maximised when we dichotomised the exposure at highest quartile versus the rest. The power was maximised when we dichotomised social position in social position 1 (executive managers) versus social positions 2-5 and tested for decision authority, and when we dichotomised social positions $1+2$ versus social positions 3-5 and tested for skill discretion. As shown in tables 4 and 5, we find no sign of synergy in terms of departure from additivity. ${ }^{10}$

Since both occupation and other causes of MI may change during follow up, disturbing the results due to misclassifications in confounders and mediators over time, analyses were repeated including only the first five years of follow up. During five years' follow up, 314 persons had an MI: 269 men and 45 women. The multivariate HR for unskilled workers versus executive managers was 1.16 (95\% CI 0.80 to 1.69). Adjusting for decision authority and skill discretion did not change these results. During five years' follow up, the association between decision authority (worst versus the rest) and risk of MI was 1.32 (1.03 to 1.69) and 1.19 ( 1.01 to 1.41) with full follow up. Skill discretion (worst versus the rest) was 1.24 (0.97 to 1.60$)$ after five years' follow up and 1.24 (1.05 to 1.46) with full follow up time.

\section{DISCUSSION}

This study shows an increased relative risk of MI with decreasing social position. We also find, by means of a jobexposure matrix, a social gradient in the exposures to decision authority, skill discretion, and job demands. We further show that low decision authority and skill discretion are associated with increased risk of MI. Only skill discretion, however, shows a clear mediating effect between social

Table 4 Hazard ratios and $95 \% \mathrm{Cl}$ of $\mathrm{Ml}$ by decision authority, dichotomised by quartiles as best versus the rest, based on 9130 men and 7086 women from the Copenhagen Centre for Prospective Population Studies

\begin{tabular}{|c|c|c|c|c|}
\hline & \multicolumn{2}{|c|}{$\begin{array}{l}\text { High decision authority (highest } \\
\text { quartile) }\end{array}$} & \multicolumn{2}{|c|}{ Low decision authority (the rest) } \\
\hline & HR & $(95 \% \mathrm{Cl})$ & HR & $(95 \%$ Cl) \\
\hline $\begin{array}{l}\text { Social position 1 } \\
\text { Social position 2-5 }\end{array}$ & $\begin{array}{l}1 \\
1.24\end{array}$ & $\overline{-}(0.6$ to 2.56$)$ & $\begin{array}{l}1.38 \\
1.41\end{array}$ & $\begin{array}{l}(1.06 \text { to } 1.8) \\
(1.11 \text { to } 1.78)\end{array}$ \\
\hline
\end{tabular}

Adjusted for cohort of investigation, age, cohabitation, and sex, as described in the text. 
Table 5 Hazard ratios and $95 \% \mathrm{Cl}$ of $\mathrm{Ml}$ by skill discretion, dichotomised by quartiles as best versus the rest, based on 9130 men and 7086 women from the Copenhagen Centre for Prospective Population Studies

\begin{tabular}{|c|c|c|c|c|}
\hline & \multicolumn{2}{|c|}{$\begin{array}{l}\text { High skill discretion (highest } \\
\text { quartile) }\end{array}$} & \multicolumn{2}{|c|}{ Low skill discretion (the rest) } \\
\hline & HR & $(95 \% \mathrm{Cl})$ & HR & $(95 \% \mathrm{Cl})$ \\
\hline $\begin{array}{l}\text { Social position 1-2 } \\
\text { Social position 3-5 }\end{array}$ & $\begin{array}{l}1 \\
1.32\end{array}$ & $\overline{(1.02 \text { to } 1.71)}$ & $\begin{array}{l}1.05 \\
1.41\end{array}$ & $\begin{array}{l}\text { (0.73 to } 1.51 \\
\text { (1.15 to } 1.73\end{array}$ \\
\hline
\end{tabular}

position and risk of MI. It is not possible to show any synergy between the effect of social position and the effect of psychosocial working conditions.

\section{Major sources of bias in the study}

The use of a job exposure matrix (JEM) instead of direct reporting of work environment for each individual reduces differential misclassification, but entails a considerable amount of non-differential misclassification, which attenuates the effect of the psychosocial work environment, and therefore also attenuates its mediating role. This is due to the fact that JEM uses the average for each occupational group, and, in some cases, the intra-group variation is large. The JEM used here does not allow for jobs to change content during follow up, but we have indications that this is a minor problem. ${ }^{41}$ Furthermore, a simplified matrix for occupations with fewer than 10 observations in the DWECS is used, which increases the degree of misclassification. Excluding those occupations from the analysis, however, made no change in the estimates (data not shown).

This misclassification issue is also related to the measurements in DWECS. The scales for work environment dimensions have Chronbach's alphas between 0.4 and 0.6 , because of a combination of low intercorrelation between some items and comparatively few items per scale. Low alphas would often tend to result in bias towards zero. ${ }^{40}$

The advantage of using JEM is that misclassification related to covariates and outcome is minimised. Features of the psychosocial work environment are structural rather than individual. Heterogeneity of psychosocial work environment cannot be excluded, but studies using self reported as well as external assessment of job strain found the same OR for diagnosed IHD among men. ${ }^{17}$

Differential susceptibility is here measured as synergy or departure from additivity of the effects of social position and the mediating psychosocial exposure. We are not assuming any "general susceptibility" related to social position, but rather that there might exist specific biological interactions between different mediating causes related to social position. The fact that we do not find any synergy might well be because it does not exist; but there are also strong sources of bias in this study, particularly when using a job exposure matrix. If the misclassification of job exposure differs across socioeconomic positions, which it might well do for reasons mentioned above, it will strongly attenuate the measure of interaction between the two. ${ }^{45}$

In addition, the job categorised social positions present potential misclassifications. The validity of the Employment Classification Module (ECM) is highest for publicly employed persons and for occupations characterised by high seniority. ${ }^{46}$ People coded "position unknown" at study entry were, if possible during the first five years, classified according to their first "known position". But this should not contribute to misclassification: first, ECM was established in 1980 and the quality improved thereafter; and second, there is some lag time in information from employer to register, especially among those privately employed. ${ }^{46}$ The social grouping in ECM might also cause some misclassification.

\section{Confounders/mediators}

Our information on cardiovascular risk factors, which seems to be related to both social position and also to be a cause of MI, was collected earlier in time than the data on occupation. In our analyses, we saw that smoking and BMI had some mediating effect, but as the occupation may have existed long before we measured these risk factors, they may still serve as both mediators and confounders. Skill discretion, on the other hand, had a significant mediating effect independent of smoking and BMI. If risk factors are treated as mediators, we see that a large part of the social difference disappears (table 3). Further, if skill discretion is included, another substantial proportion of the risk disappears. This indicates that the association between social position and risk of MI is at least partly mediated by skill discretion. However, some residual confounding cannot be ruled out. In order to account for misclassifications from changes in confounders/mediators over time, we repeated our analyses with only five years' follow up. The figures indicate that if shorter follow up means less misclassification of exposures, this does not change the results significantly.

\section{Measuring decision latitude}

We found an effect on MI risk of skill discretion and decision authority, but no effect of job demands. Skill discretion and decision authority are components of decision latitude ${ }^{47}$ but most studies do not differentiate between the two dimensions, because analyses show that these two factors are strongly correlated. ${ }^{48}$ However, earlier studies have found that the skill discretion component is particularly associated with increased risk of cardiovascular disease. ${ }^{47}$ One reason why we found hardly any effect of decision authority might be that Danish employees in general have better opportunities for participation, ${ }^{49}$ whereas skill discretion is low, especially among unskilled workers. Job demands were higher in upper social positions, but not associated with risk of MI. The result is similar to other findings and discussed in more detail by Kristensen and colleagues. ${ }^{50}$

All the limitations mentioned above represent biases towards zero. Our results, therefore, tend to under- rather than overestimate effects, underscoring the importance of skill discretion and perhaps explaining why we do not replicate the SHEEP study findings of differential susceptibility.

\section{Conclusion}

Decision authority and skill discretion are strongly related to social position, and the social gradient in risk of MI is partly mediated by skill discretion. Our study shows the importance of analysing decision authority and skill discretion separately. Improvements in psychosocial work environment, especially possibilities for skill development, could contribute to a 
reduction in the incidence of $\mathrm{MI}$ and in social inequality in MI.

\section{ACKNOWLEDGEMENTS}

The present study was supported by a grant from Copenhagen Hospital Corporation and by the Danish Heart Foundation.

\section{Authors' affiliations}

I Andersen, M Gamborg, Copenhagen Centre for Prospective Population Studies, Danish Epidemiology Science Centre, at the Institute of Preventive Medicine, H:S Kommunehospitalet, Copenhagen University Hospital, DK-1399 Copenhagen K, Denmark

H Burr, T S Kristensen, National Institute of Occupational Health, Lersø Parkalle 105, DK-2100 Copenhagen $\varnothing$, Denmark

M Osler, F Diderichsen, Copenhagen Centre for Prospective Population Studies, at the Institute of Public Health, Copenhagen University, Blegdamsvej 3, DK-2200 Copenhagen N, Denmark

E Prescott, Department of Cardiology, Rigshospitalet, Blegdamsvej 9, DK-2100 Copenhagen $\varnothing$

\section{REFERENCES}

1 Marmot MG, Shipley MJ, Rose G. Inequalities in death-specific explanations of a general pattern? Lancet 1984;1:1003-6.

2 van Rossum CT, Shipley MJ, van de MH, et al. Employment grade differences in cause specific mortality. A 25 year follow up of civil servants from the first Whitehall study. J Epidemiol Community Health 2000;54:178-84.

3 Theorell T, Tsutsumi A, Hallquist J, et al. Decision latitude, job strain, and myocardial infarction: a study of working men in Stockholm. The SHEEP Study Group. Stockholm Heart epidemiology Program. Am J Public Health 1998;88:382-8.

4 Lynch J, Krause N, Kaplan GA, et al. Workplace conditions, socioeconomic status, and the risk of mortality and acute myocardial infarction: the Kuopio Ischemic Heart Disease Risk Factor Study. Am J Public Health 1997;87:617-22

5 Kunst AE, Groenhof F, Mackenbach JP, et al. Occupational class and cause specific mortality in middle aged men in 11 European countries: comparison of population based studies. EU Working Group on Socioeconomic Inequalities in Health. BMJ 1998;316:1636-42.

6 Suadicani P, Hein HO, Gyntelberg F. Strong mediators of social inequalities in risk of ischaemic heart disease: a six-year follow-up in the Copenhagen Male Study. Int J Epidemiol 1997;26:516-22.

7 Andersen I, Osler M, Petersen L, et al. Income and risk of ischaemic heart disease in men and women in a Nordic welfare country. Int I Epidemiol 2003;32:367-74

8 Lynch JW, Kaplan GA, Cohen RD, et al. Do cardiovascular risk factors explain the relation between socioeconomic status, risk of all-cause mortality, cardiovascular mortality, and acute myocardial infarction? Am J Epidemiol 1996; 144:934-42.

9 Hallqvist J, Diderichsen F, Theorell T, Reuterwall Christina, Ahlbom A, SHEEP Study Group. Is the effect of job strain on myocardial infarction risk due to interaction between high psychological demands and low decision latitude? Results from Stockholm Heart Epidemiology Program (SHEEP). Soc Sci Med 1998;46:1405-15.

10 Rothman KJ, Greenland S. Modern Epidemiology. Washington: LippincottRaven, 1998.

11 Marmot MG, Smith GD, Stansfeld S, et al. Health inequalities among British civil servants: the Whitehall II study. Lancet 1991;337:1387-93.

12 Moller L, Kristensen TS, Hollnagel H. Social class and cardiovascular risk factors in Danish men. Scand J Soc Med 1991;19:116-26.

13 Marmot MG, Rose G, Shipley M, et al. Employment grade and coronary heart disease in British civil servants. J Epidemiol Community Health 1978;32:244-9.

14 WHO. Ecological analysis of the association between mortality and major risk factors of cardiovascular disease. The World Health Organization MONICA Project. Int J Epidemiol 1994;23:505-16.

15 Alterman T, Shekelle RB, Vernon SW, et al. Decision latitude, psychologic demand, job strain, and coronary heart disease in the Western Electric Study Am J Epidemiol 1994;139:620-7.

16 Bosma H, Marmot MG, Hemingway H, et al. Low job control and risk of coronary heart disease in Whitehall II (prospective cohort) study. BMJ 1997;314:558-65.

17 Bosma H, Peter R, Siegrist J, et al. Two alternative job stress models and the risk of coronary heart disease. Am J Public Health 1998;88:68-74

18 Hall EM, Johnson JV, Tsou TS. Women, occupation, and risk of cardiovascular morbidity and mortality. Occup Med 1993;8:709-19.

19 Hammar N, Alfredsson L, Johnson JV. Job strain, social support at work, and incidence of myocardial infarction. Occup Environ Med 1998;55:548-53.

20 Johnson J, Stewart W, Hall E, et al. Long-term psychosocial work environment and cardiovascular mortality among Swedish men. Am J Public Health 1996;86:324-31.
21 Karasek R, Baker D, Marxer F, et al. Job decision latitude, job demands, and cardiovascular disease: a prospective study of Swedish men. Am J Public Health 1981;71:694-705.

22 Kuper H, Marmot M. Job strain, job demands, decision latitude, and risk of coronary heart disease within the Whitehall II study. J Epidemiol Community Health 2003;57:147-53.

23 Reed DM, LaCroix AZ, Karasek RA, et al. Occupational strain and the incidence of coronary heart disease. Am J Epidemiol 1989; 129:495-502.

24 Sacker A, Firth D, Fitzpatrick R, et al. Comparing health inequality in men and women: prospective study of mortality 1986-96. BMJ 2000;320:1303-7.

25 Steenland K, Johnson J, Nowlin S. A follow-up study of job strain and heart disease among males in the NHANES1 population. Am $J$ Ind Med 1997; 31:256-60

26 Hemingway H, Marmot M. Evidence based cardiology: psychosocial factors in the aetiology and prognosis of coronary heart disease. Systematic review of prospective cohort studies. BMJ 1999;318:1460-7.

27 Schnall PL, Landsbergis PA, Baker D. Job strain and cardiovascular disease Annu Rev Public Health 1994;15:381-411.

28 Marmot MG, Bosma H, Hemingway $\mathrm{H}$, et al. Contribution of job control and other risk factors to social variations in coronary heart disease incidence. Lancet 1997;350:235-9.

29 Kivimaki $M$, Leino-Arjas $P$, Luukkonen $R$, et al. Work stress and risk of cardiovascular mortality: prospective cohort study of industrial employees. BMJ 2002;325:857.

30 Suadicani P, Hein HO, Gyntelberg F. Are social inequalities as associated with the risk of ischaemic heart disease a result of psychosocial working conditions? Atherosclerosis 1993;101:165-75.

31 Appleyard M, Hansen A, Schnohr P, et al. The Copenhagen City Heart Study. A book of tables with data from the first examination (1976-8) and a 5-year follow-up (1981-3). Scand J Soc Med 1981;170:1-160.

32 Suadicani P. Identification of risk factors mediating the excess risk of ischaemic heart disease in low social classes. Copenhagen University, MD Thesis, 2002.

33 Gyntelberg F. Koronar hiertesygdom og fysisk aktivitet, epidemiologiske studier til besysning a sammenhængenmellem fysisk aktivitet og risiko for koronar hiertesygdom [Coronary heart disease and physical activity, epidemiological studies to elucidate the association between physical activity and coronary heart disease]. Københavns Universitet, MD Thesis, 1975.

34 Hein HO, Suadicani P, Gyntelberg F. Alcohol consumption, serum low density lipoprotein cholesterol concentration, and risk of ischaemic heart disease: six year follow up in the Copenhagen male study. BMJ 1996;312:736-41.

35 Hagerup L, Schroll M, Hollnagel $H$, et al. The Glostrup population studies. Collection of epidemiologic tables. Reference values for use in cardiovascular population studies. Scand J Soc Med 1981;20:1-112.

36 Schroll M. The World Health Organization MONICA project (monitoring trends and determinants in cardiovascular disease): a major internationa collaboration. J Clin Epidemiol 1988;41:105-14

37 Andersen O, Laursen L, Petersen J. Occupational mortality 1981-1995. Copenhagen: Statistics Denmark, 2002.

38 Fredlund P, Hallqvist J, Diderichsen F. Psykosocial yrkesexponeringsmatris. En uppdatering av ett klassifikationssystem för yrkesrelaterade psykosociala exponeringar. Stockholm: Arbetslivsinstitutet, 2001.

39 Johnson JV, Stewart WF. Measuring work organization exposure over the life course with a job-exposure matrix. Scand J Work Environ Health 1993;19:21-8.

40 Borg V, Kristensen TS, Burr H. Work environment and changes in self-rated health: a five year follow-up study. Stress Med 2000;16:37-47.

41 Burr H, Bjorner JB, Kristensen TS, et al. Trends in the Danish work environment in 1990-2000 and their associations with labor-force changes. Scand J Work Environ Health 2003;29:270-9.

42 Madsen M, Davidsen M, Rasmussen S, et al. The validity of the diagnosis of acute myocardial infarction in routine statistics: a comparison of mortality and hospital discharge data with the Danish MONICA registry. J Clin Epidemiol 2003;56:124-30

43 Grambsch PM. Proportional hazards tests and diagnostics based on weighted residuals. Biometrika 1994;81:515-26.

44 StataCorp. Stata Statistical Software: release 7.0. Stata Corporation, College Station, TX 77845, USA, 2001

45 Lundberg M, Hallqvist J, Diderichsen F. Exposure-dependent misclassification of exposure in interaction analyses. Epidemiology 1999:10:545-9.

46 Bach E. Validering af EIR - Et arbejdsepidemiologisk monitoreringssystem [Validating the Occupational Hospitalisation File. A monitoring system of work environment epidemiology.]. University of Roskilde. The National Institute of Occupational Health, 1998.

47 Marmot M, Theorell T. Social class and cardiovascular disease: the contribution of work. Int J Health Serv 1988;18:659-74.

48 Theorell T. Working conditions and health. In: Berkmann LKI, ed. Social Epidemiology. Oxford: Oxford University Press, 2000:95-117.

49 Gallie D. The quality of working life: is Scandinavia different? European Sociological Review 2003;19:61-79.

50 Kristensen TS, Borg V, Hannerz H. Socioeconomic status and psychosocial work environment: results from a Danish national study. Scand J Public Health 2002;(suppl 59):41-8. 